\title{
Erratum to: Management of patients with T1b esophageal adenocarcinoma: a retrospective cohort study on patient management and risk of metastatic disease
}

D. W. Schölvinck ${ }^{1,2}$ - H. T. Künzli ${ }^{1,2}$ - S. L. Meijer ${ }^{3}$ - C. A. Seldenrijk ${ }^{4}$.

\author{
M. I. van Berge Henegouwen ${ }^{5}$ J. J. G. H. M. Bergman ${ }^{2}$ - B. L. A. M. Weusten ${ }^{1,2}$
}

Published online: 3 August 2016

(C) Springer Science+Business Media New York 2016

\section{Erratum to: Surg Endosc}

DOI 10.1007/s00464-016-5071-y

The initials of the authors are incorrect. They should be changed to:

D. W. Schölvinck, H. T. Künzli, S. L. Meijer, C. A. Seldenrijk, M. I. van Berge Henegouwen, J. J. G. H. M. Bergman, B. L. A. M. Weusten.

The online version of the original article can be found under doi:10.1007/s00464-016-5071-y.

\footnotetext{
B. L. A. M. Weusten

b.weusten@antoniusziekenhuis.nl

H. T. Künzli

h.t.kunzli@amc.uva.nl

1 Department of Gastroenterology and Hepatology,

St. Antonius Hospital, Nieuwegein, Nieuwegein,

The Netherlands
}

2 Department of Gastroenterology and Hepatology, Academic Medical Center Amsterdam, Meibergdreef 9,

1105 AZ Amsterdam, The Netherlands

3 Department of Pathology, Academic Medical Center Amsterdam, Amsterdam, The Netherlands

4 Department of Pathology, St. Antonius Hospital, Nieuwegein, Nieuwegein, The Netherlands

5 Department of Surgery, Academic Medical Center Amsterdam, Amsterdam, The Netherlands 